\title{
Heterotopic pregnancy with molar changes
}

\section{Meena N. Satia, Vibha More, Trupthi Ganapathi*}

Department of Obstetrics and Gynaecology, Seth G.S Medical College and KEM Hospital, Mumbai, Maharashtra, India

Received: 14 August 2016

Accepted: 12 September 2016

\section{*Correspondence:}

Dr. Trupthi Ganapathi,

E-mail: trupthi148@gmail.com

Copyright: (c) the author(s), publisher and licensee Medip Academy. This is an open-access article distributed under the terms of the Creative Commons Attribution Non-Commercial License, which permits unrestricted non-commercial use, distribution, and reproduction in any medium, provided the original work is properly cited.

\begin{abstract}
Trophoblastic disease of pregnancy is also called as gestational trophoblastic disease (GTD), a rare group of tumors that involves abnormal proliferation of the trophoblastic cells. GTD is generally benign but sometimes can be malignant due to its marked penetration into and destruction of myometrium as well as its ability to metastasize hence the groups of tumors are referred to as gestational trophoblastic neoplasm (GTN). These are among the rare tumors that can be cured even in the presence of widespread dissemination. Present study is a case of intrauterine partial mole with ectopic pregnancy in the right adnexa with vesicular changes, a rare entity in obstetrics.
\end{abstract}

Keywords: GTD, Heterotopic pregnancy, Ectopic mole

\section{INTRODUCTION}

GTD is a spectrum which consists of Vesicular mole, Invasive mole and non-molar trophoblastic neoplasms which include choriocarcinoma and placental site trophoblastic tumour (PSTT) .The characteristic finding of these tumours is raised beta human chorionic gonadotropins ( $\beta$-hCG) level, which is used not only for diagnosis but also for follow up to diagnosis of recurrence after treatment. Hydatidiform mole is the most common amongst all GTD and incidence of hydatidiform moles is $0.1 \%$ ( 1 per 1,000$)$ pregnancies.

It is further divided into partial mole and complete mole. Patients with partial mole have $1-5 \%$ changes of developing GTN, complete mole have $4-10 \%$ risk of developing metastatic tumours. ${ }^{1}$

GTN develops with or occurs after either hydatidiform mole or rarely it develops after a live birth, miscarriage, or termination. ${ }^{2}$ Ectopic pregnancy occurs in $2 \%$ of pregnancies hence the ectopic molar gestation is a rare entity. The malignant probability is almost same as that of an intrauterine molar pregnancy. ${ }^{3}$ Signs and symptoms of tubal molar pregnancy are similar to that of normal tubal ectopic pregnancy and therefore makes the diagnosis difficult.

Diagnosis of molar ectopic pregnancy becomes more difficult if it is associated with heterotopic pregnancies, where the clinical presentation may be delayed probably weeks after evacuation of the intrauterine pregnancy as is the case with our patient. Although extremely rare, an adnexal molar pregnancy should be considered as a differential diagnosis in patients with intrauterine pregnancy along with a pelvic mass, vascularity and high levels of serum $\beta-\mathrm{hCG}^{3}$

\section{CASE REPORT}

A 26 year old, patient came to out-patient department with complaints of bleeding per vaginum associated with dull aching continuous pain abdomen since 1 month. She had history of evacuation of vesicular mole 2 months ago, she had been to a private consultant with history of two months amenorrhea to confirm pregnancy. Urine pregnancy test was positive and she was advised ultrasonography. The ultrasonography report was 
suggestive of missed abortion with vesicular mole and $\beta$ hCG was 2,00,000 IU/ml.

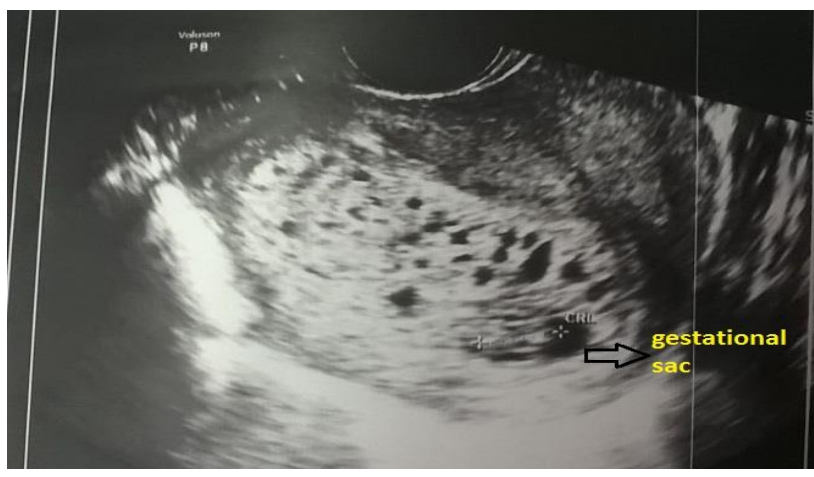

Figure 1: Ultrasonography suggestive of partial vesicular mole.

She underwent suction evacuation. Following the procedure she persistently complained of spotting per vaginum for which she was started on oral contraceptive pills and tablet Tranexamic acid. Despite of being on medication her symptoms were not relieved, hence she was advised repeat ultrasound of pelvis which revealed a mixed echogenic mass in the right adnexa of $6 \times 4 \mathrm{cms}$ with a tiny gestational sac like structure seen at the centre, of $5 \times 4 \mathrm{~mm}$, with multiple dilated tortuous vascular channels seen around the mass likely an ectopic pregnancy, the endomyometrial junction was normal with increased vascularity seen in the right cornual region of the myometrium.

Colour Doppler showed increased vascularity in the right adnexa with oedematous villous degenerations shown in the following figures. On examination her general condition was stable, she was afebrile, had tachycardia with pulse was $100 / \mathrm{min}$. No abnormality was detected on abdominal examination. Speculum examination, cervix and vagina were healthy with minimal bleeding through cervical OS.

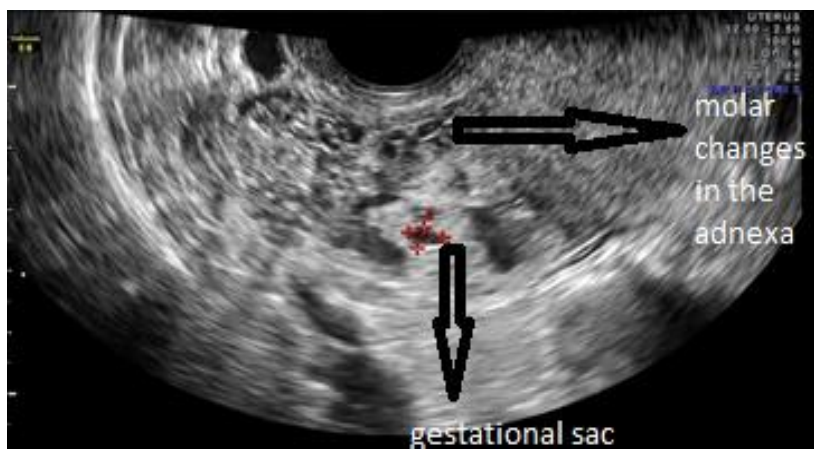

Figure 2: Adnexal mass with molar changes and a small gestational sac.

On vaginum examination, uterus was retroverted normal in size, with a right adnexal tender mass of $4 \times 4 \mathrm{~cm}$ felt. A clinical impression of ectopic pregnancy was made and she was advised ultrasonography of the pelvis. Her complete hemogram, liver function test and renal function tests were normal. Her chest X-ray and thyroid stimulating hormone were within normal limits. Her ultrasound revealed right adnexal mass with molar changes and a small gestational sac like structure seen within consistent with the previous ultrasonography report.

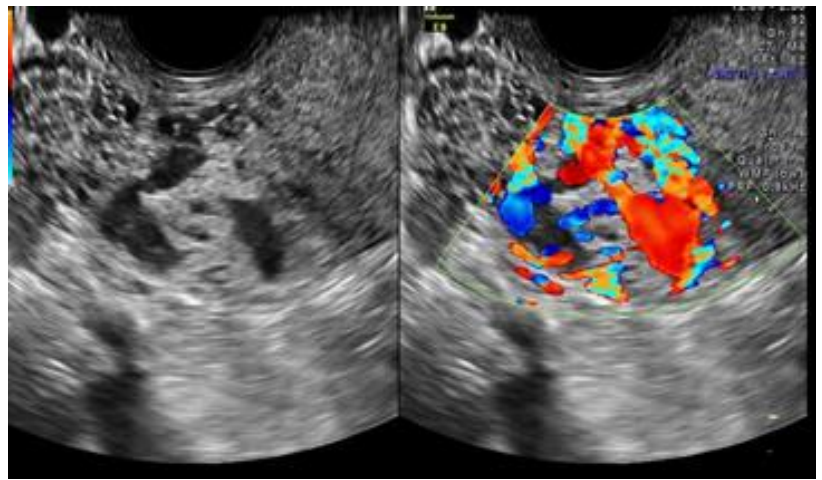

Figure 3: Highly vascular adnexal mass with molar changes.

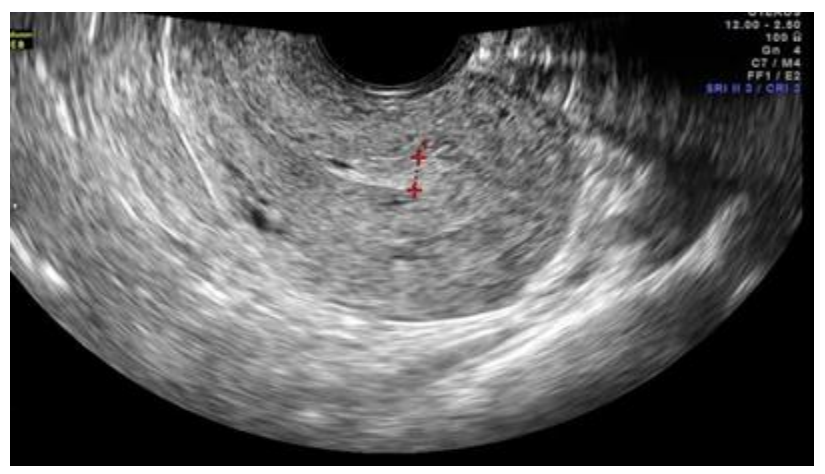

Figure 4: Normal endomyometrial junction.

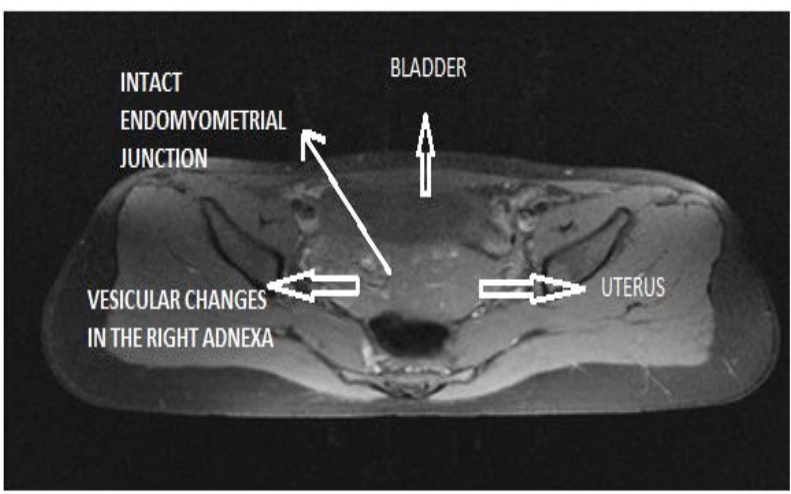

Figure 5: Right adnexal mass, central endometrium and intact right lateral wall myometrium in between.

Serum $\beta$-hCG level was 29000IU/ml. Thus differential diagnosis of

- An ectopic pregnancy with vesicular changes.

- Invasive vesicular mole from the uterus extending to the right adnexa was made. 
MRI pelvis was done which revealed uterus normal in size with a soft tissue mass in the right adnexa with hemorrhage within the lesion abutting the serosal surface of uterus with a small gestational sac seen. Thus the diagnosis of ectopic pregnancy with molar changes was made.

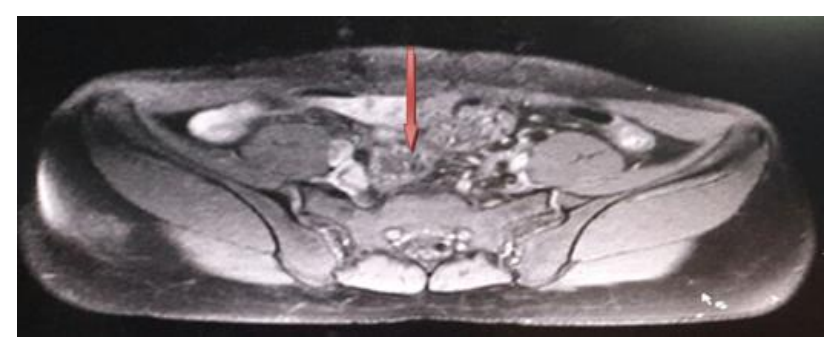

Figure 6: MRI Pelvis showing vesicular mole in the right adnexa (red arrow showing the lesion).

In view of elevated $\beta$-hCG 2 months after evacuation of a vesicular mole, ultrasound and MRI findings suggestive of molar changes in adnexal mass with patient haemodynamically stable surgical intervention was not warranted and decision was taken to start chemotherapy. Patient was referred to oncology centre where she was given 3cycles of chemotherapy with 4 doses of injection methotrexate $1 \mathrm{mg} / \mathrm{kg}$ body weight (day 1, 3, 5 and 7), alternating with injection leucovorin $15 \mathrm{mg}$ (day 2, 4, 6 and 8 ) in each cycle. She tolerated the treatment well. Her repeat $\beta$-hCG values were in reducing trend, level of $10000 \mathrm{IU} / \mathrm{ml}$ after receiving 3 doses of methotrexate of the 1 st cycle, $\beta$-hCG levels after $2^{\text {nd }}$ cycle was $345 \mathrm{IU} / \mathrm{ml}$. Patient was discharged and asked to follow up after 3rd cycle for repeat $\beta$-hCG level.

Early in the development, trophoblasts give rise to villi and it later forms the placenta which protects and nourishes the fetus, hence it is rightly said "Tropho""Blasts" means to provide nutrition to the growing fetus. A partial mole occurs when 2 sperm fertilize ovum (69XXX, 69XXY). The tumour contains few fetal tissues mixed in with the trophoblastic tissues. A complete mole develops when one or two sperm fertilize an ovum that contains no nucleus or DNA. All the genetic material are paternal in origin with mitochondrial DNA of maternal origin $(46 \mathrm{XX})$. Thus no fetal tissues formed. ${ }^{4}$ Gestation trophoblastic disease is grouped into molar and nonmolar tumours. The incidence of complete and partial mole is $1: 1945,1: 695$ pregnancies respectively. ${ }^{5}$ Ultrasound is a reliable and sensitive modality for the diagnosis of molar pregnancy. Ectopic pregnancy occurs in $2 \%$ of pregnancies and the ectopic molar gestation is very rare. The prevalence of gestational trophoblastic disease in tubal pregnancy is $1.6 \%$ of total deliveries. Sonographically, a vesicular mole, a PSTT, and choriocarcinoma display a hypo-echoic, solid mass with cystic vascular spaces, detection rates are higher for complete mole compared to partial and this improves in early second trimester. The current gold standard for identification of vesicular mole is histopathology which is characterized by the presence of hydropic change of the placental villi, along with proliferation of trophoblasts. ${ }^{6}$ Genotyping and chromosome in situ hybridization also can be used as a reliable tool to correlate the histological classification of a hydatidiform mole in cases with difficult histological evaluation. ${ }^{7}$ Because tubal implantation may be associated with decreased vascularisation, $\beta$-hCG levels are usually in the range lower as compared to intrauterine pregnancy. There is practically no difference in $\beta$-hCG levels between molar tubal pregnancies and ectopic pregnancy. Thus, tubal molar pregnancy is not distinguishable from a nontrophoblastic tubal pregnancy on the basis of $\beta$-hCG levels. ${ }^{7}$ Molar changes in tubal pregnancy are rare and only 40 cases have been reported in the world literature. ${ }^{8}$ In our case, presence of highly vascular cystic lesion in the adnexa with high $\beta$ - hCG and the good response to methotrexate is highly suggestive of molar changes in ectopic pregnancy. The pathological diagnosis of an invasive mole is very rarely made as most cases are treated with chemotherapy like in our case, patient responded very well to chemotherapeutic agents. Measurement of serum $\beta$-hCG levels combined with clinical findings and imaging modality rather than a histological specimen was used to diagnose and treat this malignancy. ${ }^{9}$ Treatment of molar ectopic pregnancy includes chemotherapy or combination of surgery and chemotherapy.

Table 1: Modified World Health Organisation (WHO) prognostic scoring system.

\begin{tabular}{|lllll|}
\hline Parameter & 0 & 1 & 2 & 4 \\
\hline Age & $<40$ & $>40$ & & \\
\hline Antecedent pregnancy & Mole & Abortion & Term & 13 and above \\
\hline Interval from index pregnancy & $<4$ & $4-7$ & $7-13$ & 105 and above \\
\hline Pretreatment serum $\beta$ hCG & $<103$ & $103-104$ & $104-105$ & \\
\hline Largest tumour size & & $3<5$ & 5 and above & \\
\hline Site of metastasis & Lung & Spleen and kidney & Gastrointestinal & Liver and brain \\
\hline No of metastasis & & $1-4$ & $5-8$ & $>8$ \\
\hline Previous failed chemotherapy & & & Single drug & 2 or more drugs \\
\hline
\end{tabular}


Since the development of chemotherapeutic agents GTN has become a curable disease even in the presence of widespread metastasis, the high mortality and morbidity due to catastrophic and uneventful haemorrhages has reduced drastically. ${ }^{1}$

The modified World Health Organisation (WHO) prognostic scoring system as adapted by the International Federation of Gynaecology and Obstetrics (FIGO) for GTN is given in Table 1. Score of 0-6 are considered to have low risk disease. 7 and above are considered as high risk disease. ${ }^{10}$

Table 2: International FIGO staging system for GTN.

\begin{tabular}{|ll|}
\hline Stages & \\
\hline Stage 1 & Disease confined to the uterus \\
\hline Stage 2 & $\begin{array}{l}\text { GTN expands outside the uterus but limited } \\
\text { to the pelvic organs }\end{array}$ \\
\hline Stage 3 & $\begin{array}{l}\text { GTN expands to lungs with or without } \\
\text { genital tract involvement }\end{array}$ \\
\hline Stage 4 & All other metastatic sites \\
\hline
\end{tabular}

Single agent chemotherapy protocols are sufficient in non-metastatic lesions/low risk GTN. Combination chemotherapy is given for high risk disease; one is EMA$\mathrm{CO}$ regimen. Adjuvant chemotherapy and radiotherapy may also be employed. ${ }^{10}$ The most common indication for surgery now in GTN is to control haemorrhage. Angiographic embolization of the uterine arteries, instead of surgical intervention have been used to control bleeding. ${ }^{11}$ Patients with GTN should have follow-up serum $\beta$-hCG levels measured once per week till nonpregnant values are reached then serum $\beta$-hCG levels should be obtained once per month for 1 year. Women with GTD should be advised to use barrier methods of contraception until $\beta$ hCG levels become normal. Single dose progesterone injection can be given. Intrauterine contraceptive devices should not be used due to the risk of uterine perforation. ${ }^{12}$

\section{CONCLUSION}

GTN are among the tumours that can be cured with chemotherapy even in the presence of widespread dissemination. Patients who have been successfully treated with GTN do not have impaired fertility and can have normal pregnancy outcome in the subsequent pregnancy.
Funding: No funding sources Conflict of interest: None declared Ethical approval: Not required

\section{REFERENCES}

1. Moon HH, Kim SM, Moon JH, Kang WD, Choi HS. Metastatic gestational trophoblastic neoplasm presenting as spontaneous renal and cerebral hemorrhage with low titer of hCG: a case report of an unusual case. Korean J Obstet Gynecol. 2012;55(10):766-71.

2. Thomakos N. Gestational trophoblastic neoplasia with retroperitoneal metastases: A fatal complication. World J Surg Onco. 2010;8:114.

3. Borah T, Raphael V, Panda S, Saharia P. Ectopic molar pregnancy: a rare entity. J Reprod Infertil. 2010;11(3):201-3.

4. Wagner SA, Keeler SM, Blank SV, Tritsch IET. Metastatic gestational trophoblastic disease following a complete hydatidiform mole coexistent with an anencephalic fetus diagnosed at 10 weeks' gestation. J Ultrasound Med 2008;27:1533-6.

5. Jonathan S. Bereck. Novak's Gynaecology. $15^{\text {th }}$ edition. NewDelhi; Lippincott Williams \& Wilkins, Wolters Kluwer publications.2012:1459.

6. Thomakos N. Gestational trophoblastic neoplasia with retroperitoneal metastases: a fatal complication. World J Surg Oncology. 2010;8:114.

7. Bousfiha N, Erarhay S, Louba A, Saadi H, Bouchikhi C, Banani A, et al. Ectopic molar pregnancy: a case report. Pan African Med J. 2012;11:63.

8. Husain N, Mishra S, Pradeep Y. Ectopic molar pregnancy mimicking choriocarcinoma. Internet $\mathrm{J}$ Gyne Obst. 2008;12(1):10-1.

9. Amandeep K, Shashi G, Vikram M, Rajni G. Invasive mole presenting as acute abdomen. Int $\mathbf{J}$ Reprod, Contra, Obst Gyn. 2011;13:35-6.

10. Corton MM. Leveno KJ, Bloom SL. Williams Obstetrics. 25 $5^{\text {th }}$ edition. NewDelhi: McGraw Hill Education.2014:403.

11. Eoh KJ, Chung YS, Yim GW, Nam EJ, Kim E, Kim $\mathrm{S}$, et al. Role of surgical therapy in the management of gestational trophoblastic neoplasia. Obstet Gynecol Sci. 2015;58(4):27783.

12. Royal college of Obstetrics and gynaecology. The Management of Gestational Trophoblastic Disease. Available at https:// www.rcog.org.uk/ globalassets/ documents/guidelines/gt38managementgestational02 10.pdf. Accessed on 4 February 2010.

Cite this article as: Satia MN, More V, Ganapathi T. Heterotopic pregnancy with molar changes. Int J Reprod Contracept Obstet Gynecol 2016;5:3630-3. 